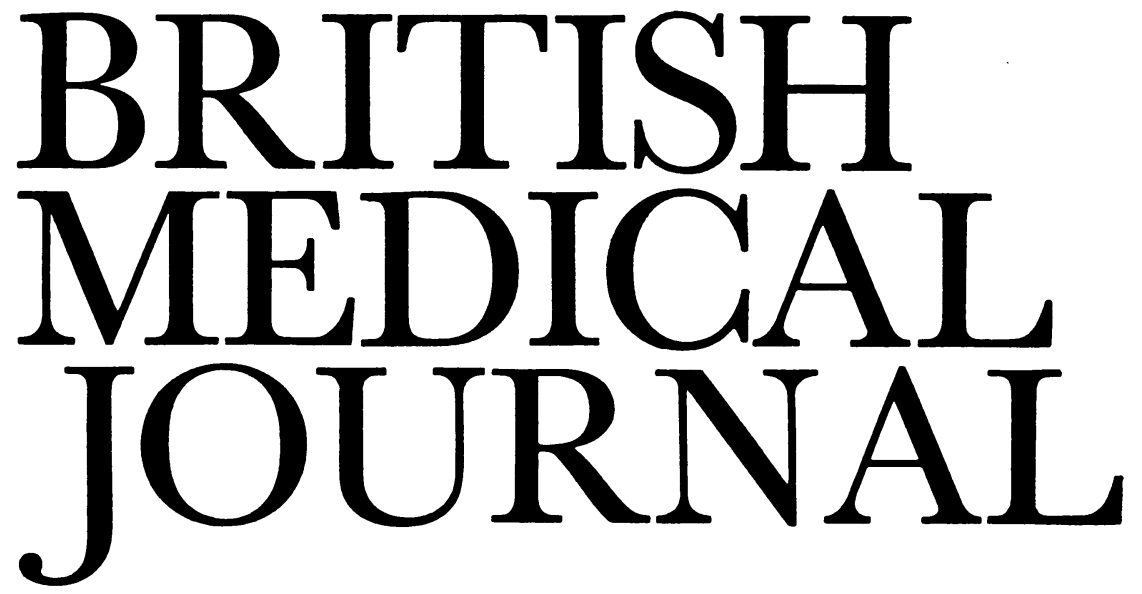

LONDON, SATURDAY 16 AUGUST 1986

\title{
Obstetric anaesthetic services
}

Anaesthetic services for obstetrics are a recurring cause for concern. A survey of services in Yorkshire ( $p$ 431) describes a picture typical of the whole country. Despite repeated recommendations to the contrary, ${ }^{12}$ small maternity units without emergency anaesthetic cover persist-albeit to the delight of the local population. Even consultant obstetric units do not always have consultant anaesthetic sessions, and there may be dangerous delay in obtaining an anaesthetist in an emergency. Epidural analgesia is still not available everywhere on request, and thus many obstetric procedures must still be carried out under general anaesthesia.

A recent survey of the 25 maternity units in the South East Thames region found 10 where epidural analgesia was not available, seven where there was no resident anaesthetist of registrar grade, two with no resident anaesthetist, and a further five small units with no emergency anaesthetic cover whatever. One of these was separated from the nearest fully equipped obstetric unit by 16 miles and a swing bridge. ${ }^{3} \mathrm{~A}$ study in the North West Thames region showed a similar proportion of centres without resident anaesthetic services, while in some major centres the designated anaesthetist was not always available for obstetric emergencies (M Frank, P Heywood, unpublished observations). Other reports attest in many centres to the absence of suitable antacid policies, lack of skilled help for the anaesthetist, and ignorance of the danger of aortocaval compression. ${ }^{3-5}$

The Social Services Committee recommended in 1980 that there should be consultant sessions in obstetric anaesthesia for every unit delivering more than 1000 women a year, that anaesthetic services should be readily available in an emergency, and that there should be an epidural service in all consultant obstetric units. By 1983-4 these recommendations had not been implemented fully in the West Midlands, Northern, and other regions. ${ }^{23}$

Why are some services so poor? Firstly, in a unit of fewer than 1500 or even 2000 deliveries a year an anaesthetist may be needed too rarely to make his continued availability economic. Even a unit of over 2000 deliveries makes rare demands on him in the absence of a full epidural service. Secondly, obstetric anaesthesia may be occasional, unpredictable, urgent, and tricky. It requires a highly trained registrar who is still fleet of foot, and this rare creature is under threat from projected manpower cuts; thus the designated obstetric anaesthetist may become extinct even in the larger units.
A junior anaesthetist should be trained in obstetrics by a consultant, not by a colleague of six months' seniority. In 1971 in a survey for the Obstetric Anaesthetists' Association I found that only half the consultant obstetric units in Britain had related consultant anaesthetic sessions. Now in some NHS units the consultant anaesthetist may be a more familiar figure than the consultant obstetrician. Yet there remains the occasional substantial unit with no consultant anaesthetic sessions. ${ }^{3}$ Without a sessional allowance time constraints militate against adequate training of juniors. Even when sessions are available, making good use of them can be difficult, and they are often diverted to anaesthetising for lists of elective caesarean sections. Thus the consultant has no opportunity other than in awkward moments to train junior staff in the much more exacting arts of emergency epidural and general anaesthesia.

Do these shortcomings matter? Maternal mortality is an insensitive index of performance, because deaths are so rare. Furthermore, examining triennial reports on confidential inquiries into maternal deaths is like star gazing: the onlooker can perceive only what happened years ago. Perinatal mortality, which is 100 times greater than maternal mortality, provides a more sensitive index of care. The anaesthetic contribution to perinatal death has been studied only regionally, ${ }^{6}$ however, and absence of emergency anaesthetic cover is the most important factor. Only maternal anaesthetic deaths are studied nationally-in the confidential inquiries. ${ }^{7}$ Over the past 30 years perinatal mortality has dropped threefold or fourfold and maternal mortality tenfold. Maternal anaesthetic deaths from all causes are also declining. Nevertheless, every death directly associated with anaesthesia is potentially avoidable, and the main causes of death are remarkably consistent: the inexperience of the anaesthetist, lack of skilled help, misplaced tracheal tubes, and inhaled stomach contents.

Five mothers in the latest report ${ }^{7}$ died from aspiration pneumonitis, and all had received magnesium trisilicate: the potential danger and apparent ineffectiveness of this particulate, bulky, and slow acting antacid have been pointed out previously. ${ }^{8}$ Though intubation problems may also arise, they can be miniminised by a failed intubation drill. ${ }^{9}$ Aspiration pneumonitis, on the other hand, might disappear with the use of $\mathrm{H}_{2}$ antagonists, which reduce volume as well as acidity, and of quick acting non-particulate antacids such 
as sodium citrate, which need not be given prophylactically. Such policies can be introduced for little cost. Poor use of drugs accounted for five further deaths, two with pancuronium and three with opioids. Three patients died from respiratory failure associated with scoliosis, a dangerous condition in pregnancy. ${ }^{10}$ These lives could probably have been saved by negative pressure ventilation during the later stages of pregnancy and after delivery, but this should not be attempted by the inexperienced.

Epidural analgesia features little in the latest published figures but will reappear in the next. Anaesthetists continue to advocate its use: is this empire building or are there good reasons? Many members of the public believe that epidural analgesia increases the need for forceps deliveries and is highly risky. With correct management of the second stage of labour, however, there is no overall increase in the forceps delivery rate, ${ }^{11-13}$ and an established epidural service is remarkably safe, ${ }^{14}$ though when epidural analgesia is used only occasionally mishaps occur. ${ }^{15}$ Even then immediate resuscitation should ensure that death or permanent brain damage do not follow. As anaesthetists may not always be to hand, training resident obstetricians in adult resuscitation should be a high priority. ${ }^{16}$

A 24 hour epidural service is not only safer; it makes better use of an anaesthetist's time, giving him a regular role in the maternity unit. Thus he is more likely to be present in an emergency. Moreover, offering epidural analgesia in all high risk labours may reduce the need for dangerous emergency general anaesthesia, and-unlike pethidine-epidural analgesia does not delay gastric emptying. Furthermore, by removing the stress of labour it inhibits adverse metabolic changes in both mother and fetus, ${ }^{17-19}$ reduces intrapartum and neontal death rates in babies born prematurely, ${ }^{20}$ and in pre-eclampsia produces haemodynamic changes favourable to both mother ${ }^{21}$ and baby. ${ }^{22}$ It also reduces the likelihood of fits $^{23}$ and the requirement for sedation with epileptogenic opioids and phenothiazine derivatives.

A full epidural service is not, however, universally available. In the 1960 s campaigning mothers proclaimed the right of every woman to have epidural anaglesia, and when bupivacaine arrived at the end of the decade this goal became feasible. Now, though epidural blockade is acknowledged by most consumers to provide the best analgesia, ${ }^{24}$ few trendy pressure groups campaign for its wider availability.

In summary, I see two priorities for improving obstetric anaesthesia. Firstly, health authorities should appoint consultants trained not only in fashionable management skills but also in obstetric anaesthesia. They can then, without extra cost to their health authorities, establish safe codes of practice and train junior staff and midwives to a high standard. The second area of concern is the small friendly maternity unit. Though it may boast a low perinatal mortality rate, the baby in trouble is commonly transferred before death, either before or after delivery. Pending the invention of a crystal ball enabling midwives to predict complications in labour with accuracy, the small unit remains a liability.

\section{FELICITY REYNOLDS}

Reader in Pharmacology applied to Anaesthesia and Consultant in charge of Obstetric Anaesthesia,

St Thomas' Hospital,

London SE1 7EH

1 Social Services Committee. Second repont 1979-80. Perinatal and neonatal mortality. London: HMSO, 1980. (Chairman Mrs Renée Short.)

2 Social Services Committee. Third report 1983-84. Perinatal and neonatal mortality: follow up London: HMSO, 1984. (Chairman Mrs Renée Short.)
3 South East Thames Regional Health Authority. Survey of anaesthetic services in the South East Thames region on behalf of the regional perinatal monitoring group. Bexhill: SE Thames RHA, 1985.

4 Ramamoorthy C. Safe obstetric anaesthesia-just an ideal? Anaesthesia 1986;41:82.

5 Moir DD. Safe obstetric anaesthesia—just an ideal? Anaesthesia 1986;41:651.

South East Thames Regional Health Authority. Confidential inquiry into perinatal death. Report of a pilot study by the regional perinatal monitoring group. Bexhill: SE Thames RHA, 1986

7 Department of Health and Social Security. Report on confidential inquiries into maternal deaths in England and Wales 1979-1981. London: HMSO, 1986. (Report on health and social subjects, England ar

8 Reynolds F. Antacids and maternal death: a sacred cow under attack. Anaesthesia 1983;38:391-2. 9 Tunstall ME. Failed intubation drill. Anaesthesia 1976;31:850.

10 Sawicka EH, Spencer GT, Branthwaite MA. Management of respiratory failure complicating

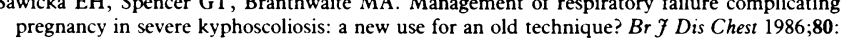
pregnancy $191-6$.

11 Phillips KC, Thomas TA. Second stage of labour with or without extradural analgesia. Anaesthesia 1983;38:972-6.

12 Maresh M, Choong KH, Beard RW. Delayed pushing with lumbar epidural analgesia in labour. Br J Obstet Gynaecol 1983;90:623-7.

13 Bailey PW, Howard FA. Epidural analgesia and forceps delivery: laying a bogey. Anaesthesia 1983;38:282-5.

14 Crawford JS. Some maternal complications of epidural analgesia for labour. Anaesthesia $1985 ; 40: 1219-25$.

15 Prince GD, McGregor DG. Epidural test dose in obstetrics. Anaesthesia 1986;41:654-5.

16 Gaylard DG, Wilson I. Resuscitation on labour wards. Anaesthesia 1986;41:651-2.

17 Pearson JF, Davies P. The effect of continuous lumbar epidural analgesia upon fetal acid-base status during the first stage of labour. Foumal of Obstetrics and Gynaecology of the British Commonwwealth 1974;81:971-4.

18 Pearson JF, Davies P. The effect of continuous lumbar epidural analgesia upon fetal acid-base status during the second stage of labour. Fournal of Obstetrics and Gynaecology of the British Commonwealth 1974;81:975-9.

19 Thalme B, Belfrage P, Raabe N. Lumbar epidural analgesia in labour. I. Acid-base balance and clinical condition of mother, fetus, and newborn child. Acta Obstet Gynecol Scand 1974;53: 27-35

20 David H, Rosen M. Perinatal mortality after epidural analgesia. Anaesthesia 1976;31:1054-9.

21 Newsome LR, Bramwell RS, Curling PE. Severe preeclampsia: hemodynamic effects of lumbar epidural anesthesia. Anesth Analg 1986;65:31-6.

22 Jouppila P, Jouppila R, Hollmen A, Koivula A. Lumbar epidural analgesia to improve intervillous blood flow during labor in severe preeclampsia. Obstet Gynecol 1982;59:158-61

23 Moir DD, Victor-Rodrigues L, Willocks J. Epidural analgesia during labour in patients with preeclampsia. Foumal of Obstetrics and Gynaecology of the British Commonwealth 1972;79:465-9. 4 Morgan BM, Bulpitt CJ, Clifton P, Lewis PJ. The consumers' attitude to obstetric care. $\mathrm{Br} \mathcal{J}$ Obstet Gynaecol 1984;91:624-8.

\section{Can we eradicate hepatitis $B$ ?}

Most acute infections are caught from chronic carriers. The prevalence of carriers of hepatitis B varies greatly: low in Western Europe and North America, 6-12\% in China, but $15-20 \%$ in some areas of west Africa and the East. Carriers who are e positive are much more infective, and an infant born to a mother who is an e positive carrier has about a $70 \%$ chance of itself becoming a chronic carrier. Virus probably gets squeezed across the placenta during birth and may be detected in cord blood by a sensitive test such as radioimmunoassay. Between $20 \%$ and $30 \%$ of children who become infected postnatally in the first two or three years of life also become chronic carriers, ${ }^{1}$ whereas only $5-10 \%$ of infected adults become carriers.

Chronic infection with hepatitis B virus may lead eventually to hepatocellular carcinoma; often in men, rarely in women. This cancer is common in China, in south east and west Africa, and in South African blacks, but much less common in whites. Studies in Taiwan showed that carriers were over 200 times more likely to develop hepatocellular carcinoma than non-carriers. ${ }^{2}$

A child born to an e negative mother rarely becomes a carrier itself, and a white carrier mother is rarely e positive. ${ }^{3}$ Nevertheless, neonatal acute hepatitis has been observed in babies born to white carrier mothers who are anti e both in Britain $^{45}$ and in the United States. ${ }^{67}$ The expression of e antigen seems to be determined genetically; most Chinese carrier women but rather fewer African carrier women are e positive-and so of children born to a Chinese carrier mother between $40 \%$ and $70 \%$ become carriers, ${ }^{8-11}$ to African mothers about $30 \%$; to Asian mothers about $6-8 \%$; and to European mothers almost none. ${ }^{8}$ 